\title{
Evaluation of Inhibition Efficiency of Oak Galls Extract as a Green Corrosion Inhibitor of Archaeological Iron Artifacts in the Atmospheric Environment
}

\author{
Yussri Salem $^{a *}$ (1) \\ ${ }^{a}$ South Valley University, Conservation Department, Faculty of Archaeology, Qena 83523, Egypt
}

Received: August 5, 2020; Accepted: October 11, 2020

\begin{abstract}
The aim of this work is to investigate the effectiveness of oak galls extract (OGE) as a green corrosion inhibitor from natural resources to prevent the corrosion of archaeological iron artifacts in atmospheric environments. The inhibition efficiency has been evaluated by measuring the weight loss of the treated coupons after exposure to $85 \% \mathrm{RH}$ in a humidity chamber, Potentiodynamic polarization and electrochemical impedance spectroscopy (EIS) techniques. Also, the morphology of an adsorbed film on the surface was investigated by scanning electron microscopy and optical microscope. The influence of OGE on changing the original appearance of the surface was also evaluated using visual examination and colorimetric measurements. The measurements results revealed that OGE gave high inhibition efficiency reaching approximately $95 \%$ of $6 \%$ concentration. Based on the study results, OGE can be proposed as an efficient green inhibitor for iron artifacts.
\end{abstract}

Keywords: oak galls, extract, a humidity chamber, weight loss, tannic acid, coupons.

\section{Introduction}

With the discovery of iron metal, many of the pieces which were made of copper and its alloys have been considered from this hard metal. However, this metal was more susceptible to corrosion than other metals ${ }^{1}$. The ancients likely conserved their iron tools against corrosion process using natural materials obtained from animals and plants. A few of these materials are still known in folklore and are available at some herbal stores as protection substances for ferrous metal. In Egypt, Afss Herb in the Arabic language is one of these substances, information is widely diffused between Egyptian Herbalists about the role of Afss herb in the protection of iron and its alloys. Also, information is circulated among chemists and archaeologist and has been reported in few studies about the role of a medium containing substances of a tannic nature like Affs in the preservation of iron artifacts in burial environments ${ }^{2}$. In several archaeological excavations, it was observed that iron artifacts remain in a good state in burial environments when they were in contact with some types of plants or woods containing tannins as major compounds. As a typical site of this type, wellpreserved iron objects were found in a Saxon tannery in York, although they were excavated after about 2000 years from burial in the soil environment ${ }^{2,3}$. Tannins are a group of phenolic compounds found in many species of plants and have a major role in protection against predation ${ }^{4,5}$. Affs is one of tannin-containing plants, and it mainly consists of tannic and gallic acid as major compounds.

This herb - under the name of Affs in Egypt- is oak tree galls and arises on young branches of the trees. This herb is known as Quercus Infectoria in Botanical name, Manjakani in Malaysia and Afss in Arabic countries. Oak trees belong to the family of Fagaceae and grow in the Mediterranean

*e-mail: Yousry.ali@arch.svu.edu.eg area, especially in Syria, Iran, Greece, and Asia Minor ${ }^{6-8}$. Oak galls were one of the common ancient herbs in Egypt, Iran, and Asia, and it have multiple therapeutic properties, so they were widely used in folklore medicine ${ }^{6,7,9}$. This study aimed to investigate oak galls as an environmentally friendly corrosion inhibitor for iron artifacts. In recent years, several studies were conducted to evaluate the inhibition efficiency of some plants and herbals extracts. These studies revealed the successful use of some herbs and plant extracts to inhibit metals corrosion in several media ${ }^{1,10-13}$. Plant extracts provide corrosion inhibitors termed as 'Green inhibitors'. Those inhibitors are non-toxic, eco-friendly and have proven to be effective in controlling the corrosion of many iron alloys. Oak galls were proposed to be tested as corrosion inhibitor of iron artifacts in this study because of common data among chemists, archaeologists, and herbalists - about the inhibition efficiency of natural substances containing tannin as major compounds. Also, in addition to this data, the main constituent of the oak galls (tannic acid) has been reported as a corrosion inhibitor for protection of mild-steel ${ }^{14}$. So, oak galls likely have good inhibition properties against corrosion of iron and its alloys and they likely will show promising results. The use of oak galls extract (OGE) as a new corrosion inhibitor was proposed in only a previous study but was for mild steel in cooling water systems ${ }^{15}$. This study represents, to our knowledge, the first actual evaluation of this extract for the protection archaeological metallic heritage.

\section{Materials and Methods}

\subsection{Preparation of Carbon steel Coupons}

Carbon steel (high and mild) is one of the most common iron used for archaeological and artistic objectives ${ }^{16}$. Coupons 
of high carbon steel (HCS) (C $3.52 \mathrm{wt} \%$ ) were cast for this study. Generally, there are two issues during the manufacturing process of metallic coupons for a scientific study; a thick slag layer usually forms on coupons as a result of the hot-dip process and the minimum thickness of samples is often greater than the required thickness. Therefore, the thickness of coupons was reduced by Lathe Machine from $1 \mathrm{~cm}$ to $2-4 \mathrm{~mm}$ and the slag layer was removed during thickness reduction. Then, the coupons were polished with different grades of emery papers (1000-3000), degreased with acetone and rinsed in distilled water before storage in a desiccator overnight.

The elemental analysis of the coupons was carried out by Energy Dispersive X-Ray fluorescence (ED-XRF) JSX 3222 Model from Jeol company, carbon element was not detected in the ED-XRF analysis (Figure 1) due to instrumental limitations of this analysis (low concentration of $\mathrm{C}$ could not be detected). So, carbon /sulfur analyzer in conjunction with inductively coupled plasma (ICP) was used to measure elemental carbon. The analysis parameters were as follows: the model: ELTRA's CS-2000, detection method: solid state infrared absorption, Number of IR cells, 1-4: Material of IR path: gold, time of analysis: $40 \mathrm{~s}$, compressed air: 4 bar/ 60 psi, and power: $230 \mathrm{~V}, 50 / 60 \mathrm{~Hz}$, max. $15 \mathrm{~A}, 3450 \mathrm{~W}$. Finally, based on the data of the engenders manufacturer and the carbon /sulphur analysis and the ED-XRF analysis, the chemical composition was C 2.52-2.9 wt\% Si 0.825, Cr 0.093, Zn $0.043, \mathrm{Au} 0.321 \mathrm{wt} \%$ and balance is of Fe. The coupons cut according to each test; they were cut to a dimension of $(7.5 \times 2.5 \times 0.12 \mathrm{~cm})$ for the environmental chamber test and $(2 \times 2 \times 1 \mathrm{~cm})$ for potentiostatic studies.

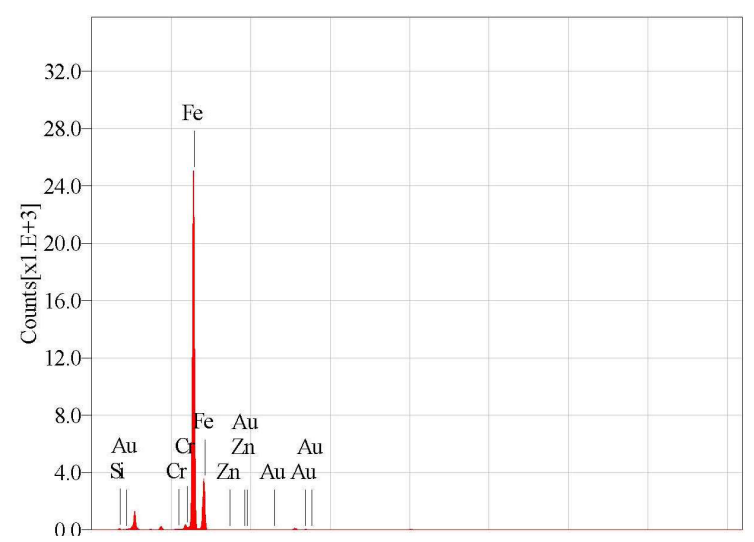

Figure 1. The elemental analysis by ED-XRF of the experimental studies coupons.

\subsection{Artificial corrosion patina of the test coupons}

The majority of archaeological iron artifacts are often covered with a corrosion patina of oxides and hydroxides. Also, there are many iron artifacts exposed to severe corrosion or mineralization whether partial or complete ${ }^{17}$. Accordingly, one of the current tests was conducted on two types of coupons: clean slandered coupons and corroded coupons with artificial patina of oxides and hydroxides as more common corrosion patinas. The oxidation or rusting occurs rapidly when the iron is exposed to humidity and air $^{18}$. So, oxides and hydroxides patina was formed on coupons by exposure to the humidity chamber test. The coupons were hanged in desiccators and exposed to $30{ }^{\circ} \mathrm{C}$ and $100 \% \mathrm{RH}$ for 28 days $^{18-20}$.

\subsection{Preparation and characterization of methanolic extract of Mazuj galls}

Oak galls were purchased locally from an Egyptian herbs' store in Luxor city. After washing, the galls were ground into a powder then were soaked in absolute methanol with the ratio of 1 gram of powder with $10 \mathrm{ml}$ of methanol for 20 hours at room temperature. Then the mixture was continuously shaken for three continuous days and at last filtered. Methanol was evaporated from the soaking solution of oak galls using an IKA rotary evaporator (Germany). Finally, the yellowish powder extract was collected from the inside of the flask of the evaporator and used for the study as shown in Figure 29,15,21,22. Three concentrations (2, 4 , and $6 \%$ ) with absolute methanol were prepared for this study. Applying the inhibitor solution on the coupons was with a single layer by a brush, since the double layer or the use of higher concentrations caused a relative color change. Reviewing some previous studies, that included the analysis of oak galls, was used to identify the chemical composition and determine constituents responsible for corrosion inhibition.

\subsection{The effect of $O G E$ on the original appearance of surface}

As a main requirement, coatings or inhibitors of archaeological metallic should have little to no effect on the surface appearance ${ }^{23}$. The corroded and un-corroded coupons were treated with the extract and were visually observed in order to record any color change of the surface appearance after applying OGE. Also, colorimetric measurements were carried out to evaluate a color change of the treated coupons. The chromatic change $\Delta \mathrm{E}$ was conducted using Optimatch 3100 device. The calculation of color change was performed according to Equation $1^{24}$ :

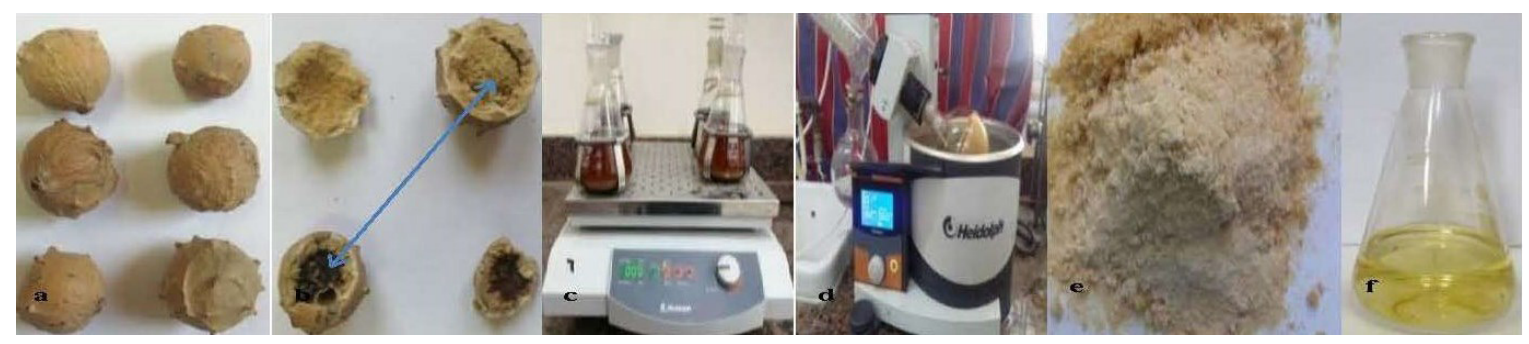

Figure 2. The preparation stages of oak galls extract powder, (a and b) oak galls with natural gummy core, (c) the soaked oak galls in absolute methanol on shaker, (d) during the extraction of the powder from methanol solution by rotary evaporator, (e) OGE powder, (f) the methanolic extract solution. 
$\Delta E^{*}=\sqrt{\left[\left(\Delta L^{*}\right)^{2}+\left(\Delta a^{*}\right)^{2}+\left(\Delta b^{*}\right)^{2}\right]}$

L: Brightness, a: Change of color from red (+value) to green (-value), b: Change of color from yellow (+value) to blue (-value), $\Delta \mathrm{E}$ : Total chromatic change of the treated and untreated coupons.

\subsection{Microscopic examination of the adsorbed inhibitor layer on the surface}

The examination of treated surfaces with a corrosion inhibitor can reveal good evidences for the evaluation of the inhibition efficiency and corrosion resistance as follows:

- Formation, Distribution and diffusion on a metal surface

- The rate of covering and adsorption of inhibitor molecules on the surface

- Cracks and fissures in corrosion inhibitor layer

Therefore, microscopic examination can be used as an initial evaluation method of the inhibition efficiency. The investigation of studied inhibitor morphology on coupons surfaces after treatment with the extract was carried out by scanning electron microscope (SEM) model JEOL-JSM 5500 and polarized light microscope model an Olympus BX51 with an Olympus DP70 camera.

\subsection{Environmental chamber test}

This test was carried out in order to determine the percentage of inhibition and corrosion rate. Also, the test provided direct results of the effect of atmospheric environment on iron corrosion in the presence of OGE. In this test, the strongest corrosion factors of metallic artifacts in an indoor museum environment was simulated. The museum environment provides metallic artifacts with the protection against many damage factors that affect the artifacts in the outdoor environment such as frost, dew, rain and high concentrations of air pollutants ${ }^{25}$. Nevertheless, there are some factors that can increase the activity of corrosion reaction such as relative humidity - especially in storage rooms - and some indoor pollutants ${ }^{26,27}$. The corrosion of iron artifacts in the museum environment depends on a chemical reaction with the main compositions of air: oxygen, humidity, and gaseous pollutants ${ }^{27}$. So, the use of relative humidity as a corrosive medium for the evaluation of inhibition efficiency is more realistic of indoor museum environment especially of humid storage conditions ${ }^{19}$. Acidic corrosive media, which were used in many previous studies, is unsuitable for archaeological objects ${ }^{28-31}$ because most of these studies were conducted in order to protect metals and alloys in industrial conditions. These alloys are already exposed to acidic media but archaeological artifacts which displayed or stored in museums are not exposed to such media.

The basic methodology of this test can be found in ASTM D1735-0 $4^{20,32}$. A desiccator (300 $\mathrm{mm}$ in diameter) was used as a chamber for the humidity and temperature. The minimum relative humidity necessary to promote the oxidation process is $65 \%$, but it can be lower in the presence of corrosive factors ${ }^{18}$. Relative humidity was adjusted at about $84 \%$ by a $250 \mathrm{ml}$ beaker containing a saturated solution of potassium chloride ${ }^{19}$. Three coupons were used for each concentration as well as three untreated coupons. The coupons were placed vertically in the middle of the desiccator and kept at room temperature during the test period. The experiment was stopped after 15 days when various corrosion signs appeared on the untreated coupons. The stop was decided based on the formation of corrosion patina on the untreated surface, which helps the inhibition efficiency can be evaluated. Finally, the coupons were removed from the test chamber and weighed again to determine the total weight loss of coupons.

The inhibitor efficiency of the extract after the humidity chamber test was evaluated by weight loss measurements, visual investigation, and microscopic examination of the coupons' surfaces using a polarized light microscope. The weight loss measurements were obtained according to ASTM G31-72 which is the standard methodology for this technique in a laboratory ${ }^{15}$. A sensitive electronic balance was used to measure the weight before and after the exposure. The weight loss $(\Delta \mathrm{W})$ of the coupons was calculated by using Equation $2^{21}$.

Weight loss $(\Delta W)=W_{1}-W_{2}$

Where $W_{1}$ is the initial weight of the coupons before the exposure to relative humidity and $\mathrm{W}_{2}$ is the final weight after the exposure. Once the weight loss value was measured, the corrosion rate $(\mathrm{CR})$ in $\left(\mathrm{mg} \mathrm{cm} \mathrm{cm}^{-2} \mathrm{~h}^{-1}\right)$ was calculated according to Equation $3^{21}$. The inhibition efficiency depends on the degree of the surface coverage $(\Theta)^{21}$ and can be expressed using Equation $4^{15}$. The percentage of inhibition efficiency (IE) was calculated from the weight loss (mg) (Equation 5) $)^{33,34}$ or corrosion rate (Equation 6$)^{33,34}$, and the result was similar.

$C R=\frac{\Delta w}{A x T}$

$\theta=\frac{\left(C R^{o}-C R^{i}\right)}{C R^{o}}$

$I E \%=\frac{\left(W^{o}-W i\right)}{W^{o}} \times 100=\frac{\left(C R^{o}-C R^{i}\right)}{C R^{o}} \times 100$

Where $\Delta \mathrm{W}$ is the weight loss (mg), A is Area of metal exposed to corrosive media $\left(82 \mathrm{~cm}^{2}\right), \mathrm{T}$ is the test period $(360 \mathrm{~h})$, $\mathrm{W}^{\circ}$ and $\mathrm{Wi}$ are the weight loss in absence and presence of inhibitor, $\mathrm{CR}^{\mathrm{o}}$ and $\mathrm{CR}^{\mathrm{i}}$ are the corrosion rate $\left(\mathrm{mg} \mathrm{cm}^{-2} \mathrm{~h}^{-1}\right)$ in absence and presence the inhibitor.

\subsection{Electrochemical measurements \\ (potentiodynamic polarization, electrochemical impedance spectroscopy, EIS)}

The electrochemical measurements were performed using an IVIUMSTAT potentiostat-galvanostat operated under computer control. A three-electrode electrochemical cell was used: Platinum as counter electrode, Silver Silver chloride $[\mathrm{Ag} / \mathrm{AgCl}]$ as reference electrode and iron coupons as a working electrode. The coupons were cut $2 \mathrm{~cm}^{2}$ with dimension for electrical connection. Tafel polarization curves were obtained at a potential range of $(-500)$ to $(500)$ 
$\mathrm{mV}$ with a scan rate $0.001 \mathrm{~V} / \mathrm{s}$. A sinusoidal signal with amplitude of $10 \mathrm{mV}$ was used to conduct EIS measurements at open-circuit potential over the frequency range of $35 \mathrm{kHz}$ down to $100 \mathrm{mHz}$. EIS' circuit was CDC R1[C1[w1R2]] model $\mathrm{R} 1+\mathrm{C} 1 *[\mathrm{~W} 1+\mathrm{R} 2]$. All experiments were performed at room temperature. Each concentration was measured three times at the same conditions for acquire reliable data, the difference between values were smaller than $5 \%$, indicating good reproducibility. The average of the values was used for the EIS data ${ }^{21}$. To gain corrosive conditions similar to the atmospheric environment, the electrochemical measurements were performed in ASTM D1384-87 standard solution. It is consisting of $148 \mathrm{mgl}^{-1} \mathrm{Na}_{2} \mathrm{SO}_{4}, 138 \mathrm{mgl}^{-1} \mathrm{NaHCO}_{3}$ and $165 \mathrm{mgl}^{-1} \mathrm{NaCl}$ with tap water ${ }^{35}$. The presence of carbonate ions and sulphate represents the natural composition of air polluted by $\mathrm{CO}_{2}$ and $\mathrm{SO}_{2}$. The inhibition efficiency IE\% from potentiodynamic polarization test was evaluated using Equation $7^{21,36}$.

$I E=\frac{\left(\text { Icorr }^{\circ}-\text { Icorr }\right)}{\text { Icorr }^{\circ}} \times 100$

Where, $\left(\right.$ Icorr $\left.^{\circ}\right)$ and (Icorr) are corrosion current densities of coupons in the absence and presence of the inhibitor. While, The inhibition efficiency from EIS measurements IE\% was calculated using Equation $8^{21}$.

$I E=\frac{\left(R^{o}-R\right)}{R^{o}} \times 100$

Where, $\left(\mathrm{R}^{\circ}\right)$ and $(\mathrm{R})$ are the polarization resistance of coupons in the absence and presence of the inhibitor.

\section{Results and Discussion}

\subsection{The chemical composition of oak galls extract}

Many studies analyzed oak galls using Gas chromatographymass spectrometry (GC-MS) and indicated that the main constituents of oak galls are tannic acid $\mathrm{C}_{76} \mathrm{H}_{52} \mathrm{O}_{46}(50-70 \%)$, gallic acid (2-4\%) $\mathrm{C}_{7} \mathrm{H}_{6} \mathrm{O}_{5}$, and ellagic acid $\mathrm{C}_{14} \mathrm{H}_{6} \mathrm{O}_{8}$ in addition to small amounts of flavonoids, saponins, alkaloids, carbohydrates, Gum, starch, and sugar ${ }^{15,22,37,38}$.

\subsection{Morphology of the adsorbed inhibitor on the surface}

The data micrograph in Figure 3 shows to promising results of OGE as a good corrosion inhibitor. The examination revealed many good properties of the deposited inhibitor layer such as the distribution and diffusion on the surface, the rate of coverage, the adsorption behavior of inhibitor molecules on metal surface, thickness homogeneity of the deposited layer, and small and well-packed structures morphology. Such good properties should be present in corrosion inhibitors for archaeological metals. So, this result is a good initial evidence of the efficiency of OGE as a corrosion inhibitor.

\subsection{The influence of OGE on the original surface appearance}

The main role of the coating or corrosion inhibitor of archaeological metallic artifacts is the protection of surface with no change in the original appearance ${ }^{39}$. The change in surface appearance is not acceptable whether it is a bad change or a good aesthetic change because the purpose of the coating is the protection rather than decoration.

Although the color of OGE solution was light yellowish (as shown in Figure 2f), the difference between treated and untreated surfaces was only in the occurrence of a slightly darkness color on the surface of treated coupons (as shown in Figure 4). Thus, it did not induce a change in the surface appearance of the samples, whether the surface was corroded or un-corrode. Color change is expressed by the $\Delta \mathrm{E}$ parameter as shown in Table 1. It was found that the treated coupons showed slight changes. The lowest change in color was at $4 \%$ concentration and $\Delta \mathrm{E}$ value was 2.54 .

Also, the visual investigation of the adsorbed film revealed good results of some properties which must be taken into consideration when choosing a corrosion inhibitor for archaeological artifacts such as:

- Low and uniform layer thickness.

- Smooth texture produces uniform color.

- Does not cause glossiness or luster of the surface

\subsection{Environmental chamber test}

\subsubsection{Weight loss measurement}

The results of weight loss measurements of the exposed coupons (clean and corroded) to the humidity chamber test in the absence and presence of OGE are shown in Table 2. First, for the clean coupons, the results show that the three concentrations inhibit the corrosion of clean coupons in the humidity chamber test. The inhibition efficiency increased with the increase in OGE concentration and thus the corrosion rate and weight loss were decreased as shown in Table 2.

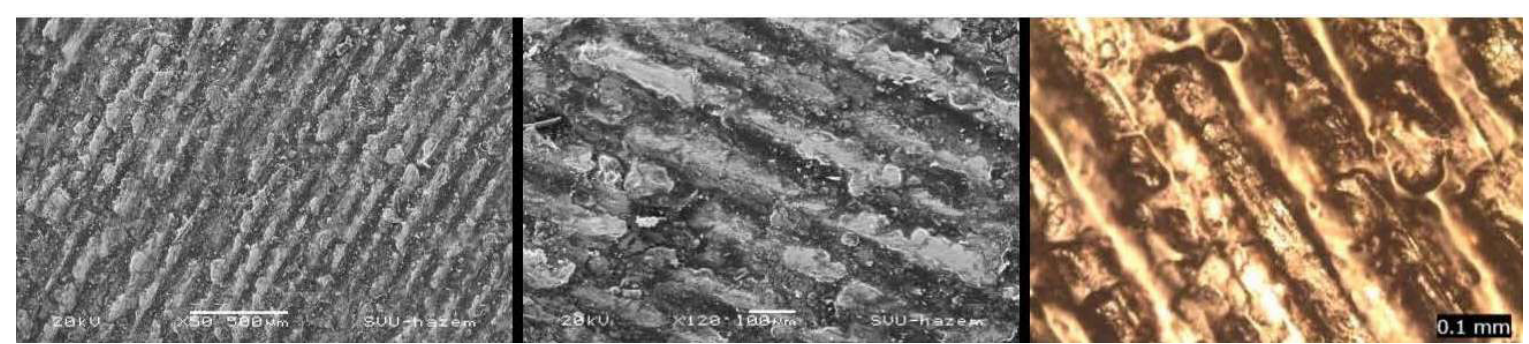

Figure 3. SEM and PM show the morphology of OGE on the surface of high carbon steel coupons; the investigation reveals homogeneous thickness and high coverage rate. 

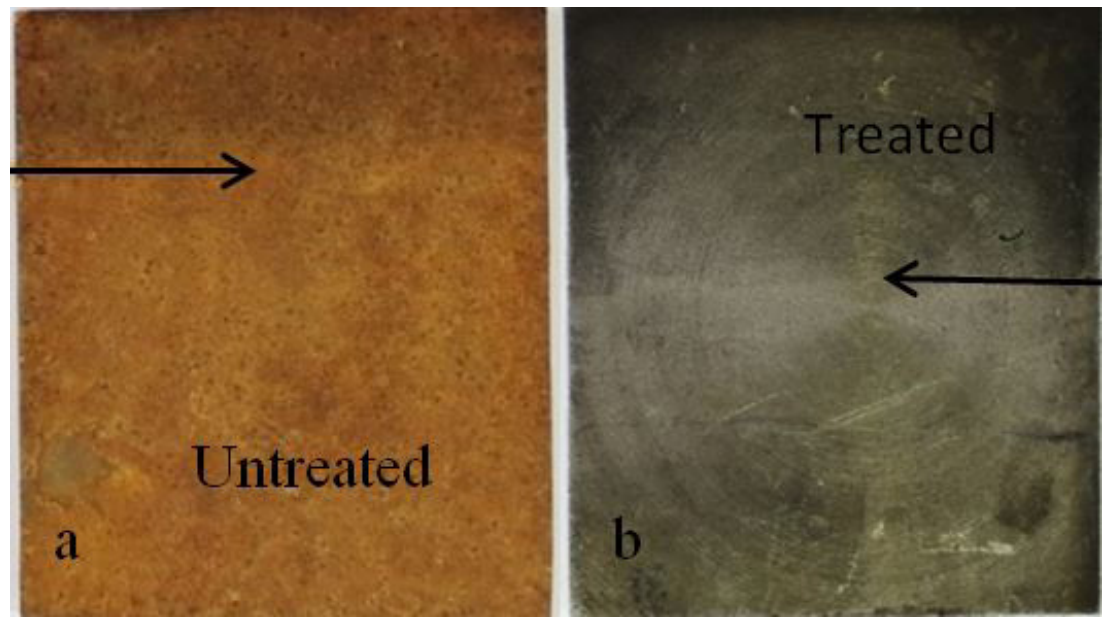

Figure 4. The appearance of the studied coupons, (a) an artificial corroded coupon and (b) a clean coupon, the area above the arrow in the two coupons is treated with OGE while the down is untreated.

Table 1. Values of the color change of treated coupons with OGE.

\begin{tabular}{|c|c|c|c|c|c|c|c|c|c|c|c|c|c|c|}
\hline \multirow[t]{2}{*}{ Con. } & \multicolumn{3}{|c|}{ Un-corroded coupons } & \multicolumn{4}{|c|}{ Color change of un-corroded } & \multicolumn{3}{|c|}{ Corroded coupons } & \multicolumn{4}{|c|}{$\begin{array}{l}\text { Color change of Corroded } \\
\text { coupons }\end{array}$} \\
\hline & $\mathrm{L}$ & $\mathrm{a}$ & $\mathrm{b}$ & $\Delta \mathrm{L}$ & $\Delta \mathrm{a}$ & $\Delta \mathrm{b}$ & $\Delta \mathrm{E}$ & $\mathrm{L}$ & $\mathrm{a}$ & $\mathrm{b}$ & $\Delta \mathrm{L}$ & $\Delta \mathrm{a}$ & $\Delta \mathrm{b}$ & $\Delta \mathrm{E}$ \\
\hline Untra. & 35 & -1 & 11 & --- & --- & --- & --- & 20 & 14 & 13 & --- & --- & --- & --- \\
\hline $2 \%$ & 33 & 17 & 20 & 2 & 18 & 9 & 20.2 & 28 & 8 & 4 & 8 & -6 & 5 & 11.1 \\
\hline $4 \%$ & 30 & 12 & 15 & 5 & 13 & 4 & 14.5 & 28 & 7 & 4 & 8 & -7 & 5 & 11.7 \\
\hline $6 \%$ & 33 & 17 & 20 & 2 & 18 & 9 & 20.2 & 26 & 5 & 5 & 6 & -9 & 8 & 13.5 \\
\hline
\end{tabular}

Table 2. Shows the results of humidity chamber test of the coupons with and without OGE.

\begin{tabular}{|c|c|c|c|c|c|c|c|c|}
\hline \multirow{2}{*}{ Conc. } & \multicolumn{4}{|c|}{ corroded coupons } & \multicolumn{4}{|c|}{ clean coupons } \\
\hline & Weight loss $(\mathrm{g})$ & IE $\%$ & Rcorr $\mathrm{mg} \mathrm{cm}^{-2} \mathrm{~h}^{-1}$ & $\theta$ & Weight loss $(\mathrm{g})$ & IE $\%$ & Rcorr $\mathrm{mg} \mathrm{cm} \mathrm{cm}^{-2} \mathrm{~h}^{-1}$ & $\theta$ \\
\hline Untre. & 2.65 & --- & .0089 & --- & 1.21 & --- & 0.0040 & --- \\
\hline $2 \%$ & 1.02 & 61.5 & .0034 & 0.616 & 0.12 & 90 & 0.0004 & 0.90 \\
\hline $4 \%$ & 1.34 & 49.4 & .0045 & 0.49 .4 & 0.06 & 95 & 0.0002 & 0.95 \\
\hline $6 \%$ & 0.96 & 63.7 & .0032 & 0.63 & 0.05 & 95 & 0.0002 & 0.95 \\
\hline
\end{tabular}

The maximum value of inhibition efficiency was $95 \%$ at 4 and $6 \%$ concentrations. Increasing the concentration beyond $4 \%$ did not cause any significant increase in the inhibition efficiency nor diminish its. This may be attributed to the withdrawal of adsorbate back into the bulk solution when the inhibitor concentrations exceeded the critical concentration ${ }^{20}$. Second, for the corroded coupons, the values of inhibition efficiency of the extract on corroded coupons were medium and did not depend on extract concentration.

\subsubsection{Surface appearance investigation}

The photographic data of the coupons after a humidity chamber test is shown in Figure 4. The comparison between the surface appearance of the coupons before and after the test revealed that:

- Generally, treated clean coupons revealed significant inhibition efficiency against humidity especially in higher concentrations, while untreated clean coupons were exposed to severe corrosion. The inhibitor efficiency was also acceptable at concentrations of 2 and $4 \%$ where the corrosion process appeared in a small area on one sample of each concentration as shown in Figure 5.

- All corroded coupons were affected by moisture, and the corrosion patina became wet and more powdery.

Polarizing microscope investigation of the treated surface before a humidity chamber test revealed that the absorbent inhibitor showed light color while the metallic surface showed dark color (Figure 6a and b). After the test, the investigation revealed that although the protection film under the microscope became more darker, corrosion did not occur especially in $6 \%$ concentration (Figure $6 \mathrm{c}$ and $\mathrm{d}$ ). This darkness decreased with an increase in inhibitor concentration. Also, although few brown corrosion spots were noted on a coupon due to exposure to concentrations of 2 and $4 \%$, (Figure 6e-g), the inhibition efficiency was high for both of the two concentrations.

Corroded coupons showed inhibition efficiency lower than clean coupons, the artificial patina has absorbed moisture and turned into a fragile and grainy layer. Generally, inhibition efficiency of the corroded coupons was weak and the isolation process of the surface from the humidity was 


\section{Corroded coupons}

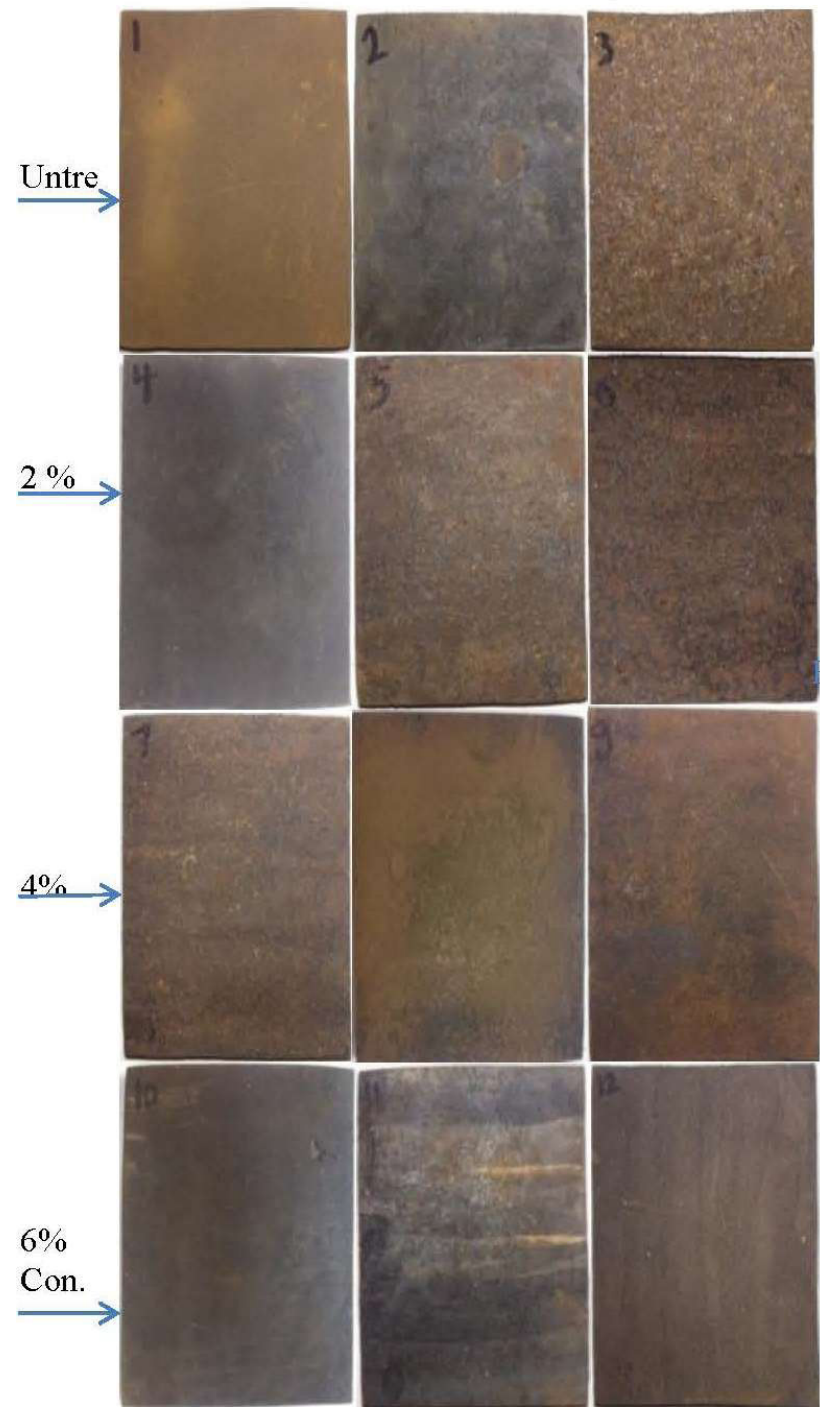

Un-corroded coupons

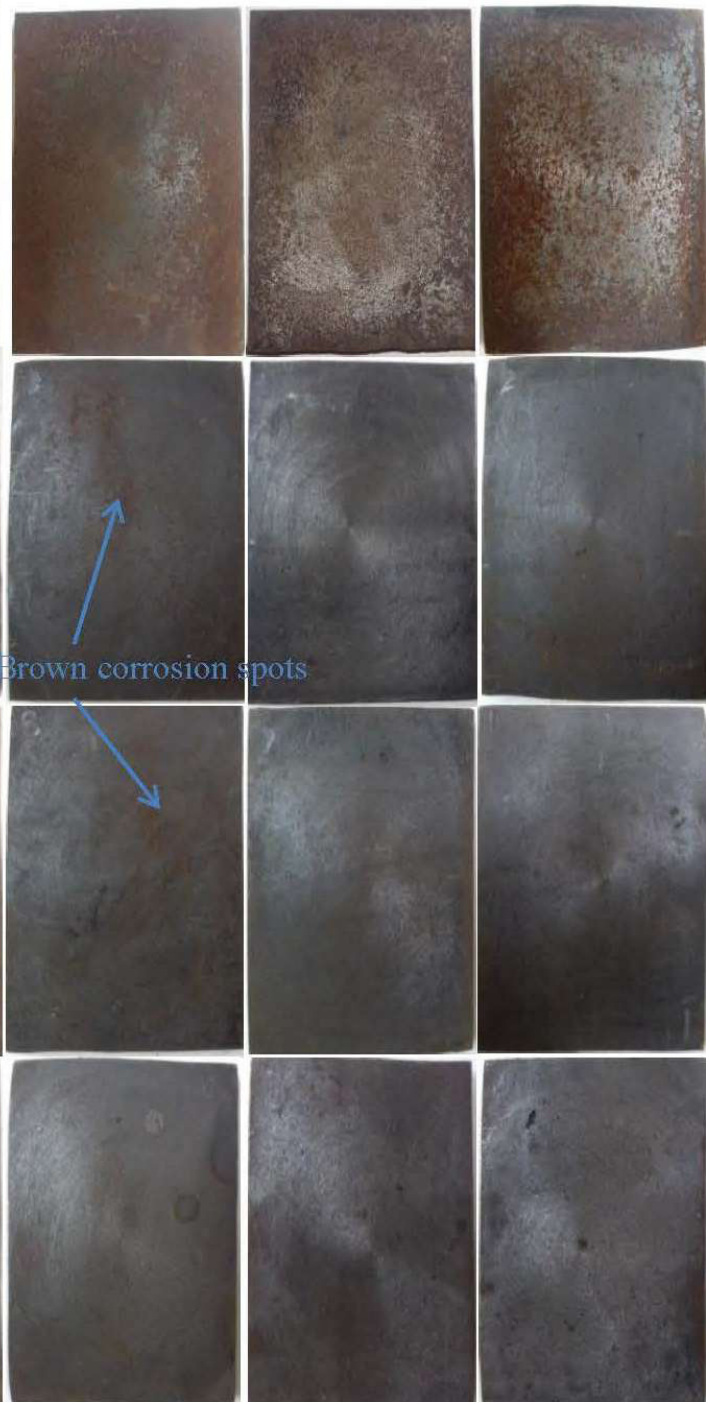

Figure 5. Treated and untreated coupons with OGE in the presence (left) and absence (right) of corrosion patina after the humidity chamber test. All corroded coupons were affected by moisture, and the corrosion patina became wet and more powdery while the treated clean coupons revealed high inhibition efficiency compared with untreated coupons.

not enough. Weak protection can not be attributed only to the extract properties, but also to the nature of the patina formed. Although various methods were used for simulation archaeological corrosion layer, an artificial patina was not comparable to an authentic layer formed on archaeological objects. The synthetic patina on the surface showed weak adhesion, granular texture, and easy exfoliation from the surface. The formed patina on studied coupons did not cover uniformly the surface of coupons and nor go deep into the metallic core.

\subsection{Electrochemical Measurements (potentiodynamic polarization and electrochemical impedance spectroscopy)}

Figure 7 shows the polarization curves of OGE with and without various concentrations. The Table 3 shows measured polarization data such as the corrosion potential $\left(\mathrm{E}_{\text {corr }}\right)$, The corrosion current density $\left(\mathrm{j}_{\text {corr }}\right)$, The cathodic Tafel slope $\left(\beta_{\mathrm{c}}\right)$, the anodic Tafel slope $\left(\beta_{\mathrm{a}}\right)$ and inhibition efficiency (IE\%).

The calculated inhibition efficiency was based on $\mathrm{j}_{\text {corr }}$ values obtained in the absence and presence of the extract. It is clear from the data in Table 3 that the increase in the concentration of the extract decreased corrosion current density and increased inhibition performance. The highest resistance (90\%) occurred at the highest concentration (i.e. $6 \%$ ) and the lowest value was at $2 \%$. The order of the inhibition efficiency IE $\%$ was $6 \%(90)>4 \%(88)>2 \%(87.6 \%)$. The results showed that the methanolic extract had good preventive properties against iron corrosion. Furthermore, as shown in Table 3, the values of the anodic and cathodic Tafel constants indicated that there was no dominant effect in both electrodes in the suppressing corrosion reactions, prevention of reaction occurred at both electrodes $\left(\beta_{\mathrm{a}}\right.$ and $\beta_{\mathrm{c}}$ ), and the inhibition efficiency did not increase significantly with increasing the concentration of 

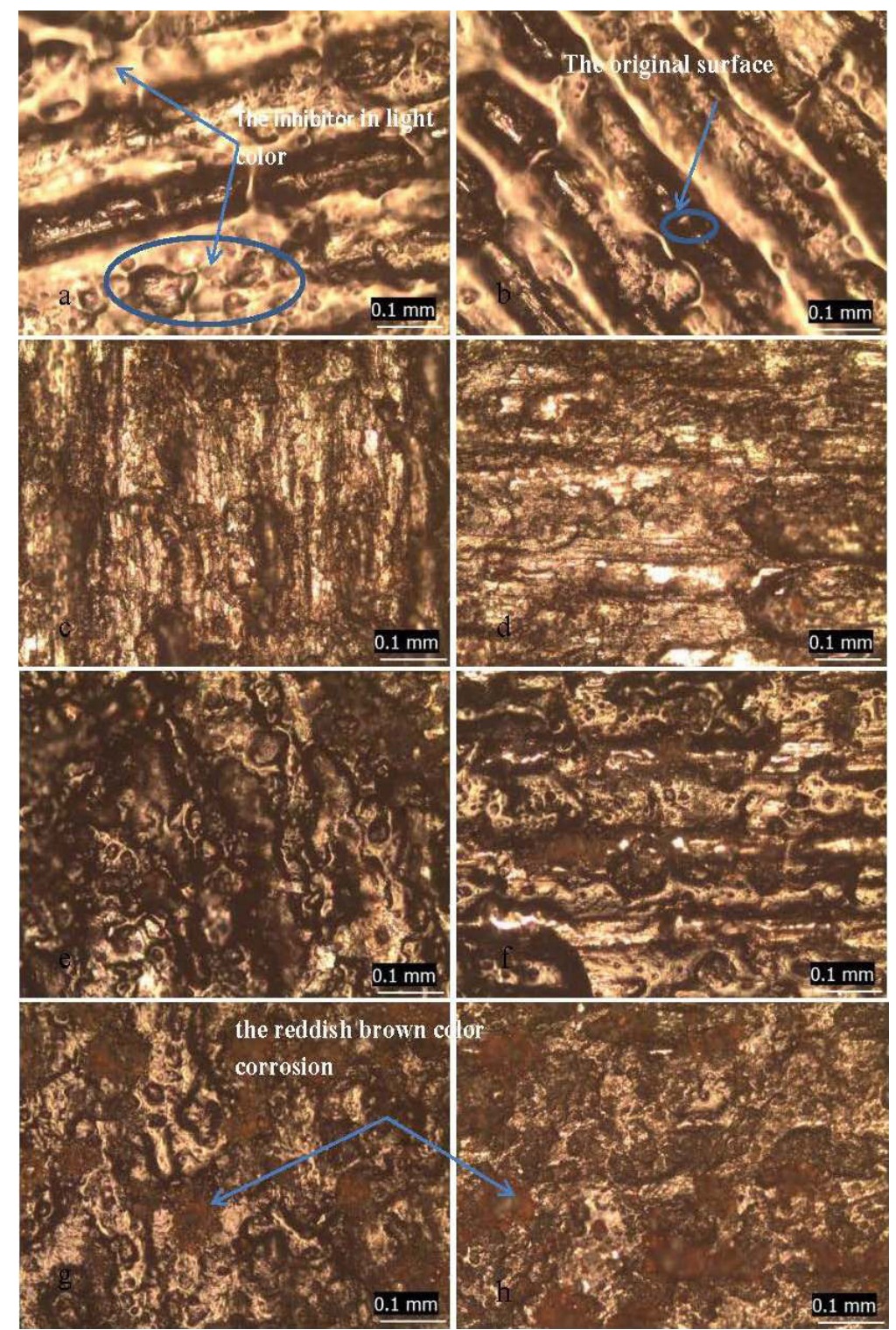

Figure 6. PM of the coupons before and after humidity chamber test: (a) and (b) before the test, (c) and (d) $6 \%$ con., (e) $4 \%$ con., (f) $2 \%$ con. and $(\mathrm{g})$ and $(\mathrm{h})$ untreated. The inhibitor on the surface appeared under the microscope in a light color while the original surface showed a dark color. The reddish-brown color indicates the occurrence of the corrosion process.

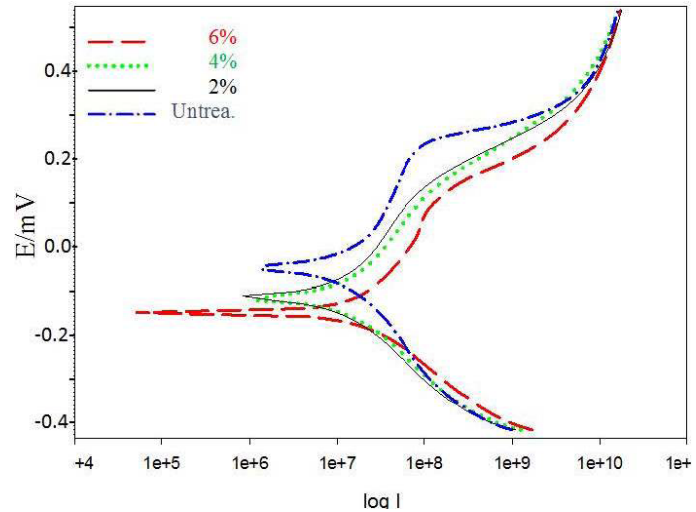

Figure 7. Polarization curves of the coupons in the absence and presence of varying concentrations of OGE. inhibitor. Thus, this suggested that the inhibitor behaved as a mixed-type inhibitor ${ }^{36}$.

Table 4 and Figure 8 show the impedance data and Nyquist plots of EIS in the absence and presence OGE, where $R_{p}$ $\left(R_{c t}\right)$ is the charge transfer resistance (can be defined also as the polarization resistances) for uninhibited and inhibited solutions, respectively. $\mathrm{R}_{\mathrm{s}}$ is the electrolyte resistance $\left(\mathrm{X} \mathrm{cm}^{2}\right)$ and $(\mathrm{Cdl})$ is the double-layer capacitance. The general rate of the polarization resistances of the three concentrations is medium. The inhibition efficiency values (IE) of EIS test were lower than both values of Potntiodinamic test and weight loss with clean coupons (Figure 9). The highest value of EIS was $70 \%$ at $6 \%$ concentration.

The Nyquist plots (Figure 8) are characterized by a depressed semicircle. This shape of Nyquist plots appears 
Table 3. Electrochemical polarization parameters obtained from Tafel plots in the absence and presence of OGE with the three studied concentrations.

\begin{tabular}{ccccccc}
\hline Con. & $\mathrm{I}_{\text {corr. }} \mu \mathrm{A} / \mathrm{cm}^{-2}$ & $-\mathrm{E}_{\text {corr }} / \mathrm{V}$ & $\beta_{\mathrm{a}} / \mathrm{V} \mathrm{dec}^{-1}$ & $\beta_{\mathrm{c}} / \mathrm{V} \mathrm{dec}{ }^{-1}$ & $\mathrm{C}$ Rate $\mathrm{mm} / \mathrm{y}$ & $\mathrm{E}_{\text {Tafel }} / \%$ \\
\hline Untrea. & .3901 & -0.1184 & .096 & .097 & 0.3302 & -- \\
\hline $2 \%$ & .0494 & -0.1838 & 0.143 & 0.129 & 0.0373 & $87.6 \%$ \\
\hline $4 \%$ & .0437 & -0.190 & .133 & .112 & .0405 & $88.7 \%$ \\
\hline $6 \%$ & .0391 & -0.222 & .094 & .074 & .0444 & $90 \%$ \\
\hline
\end{tabular}

Table 4. Shows electrochemical parameters calculated from EIS measurements.

\begin{tabular}{ccccc}
\hline Con. & $\mathrm{R}_{\mathrm{s}}(\mathrm{X} \mathrm{cm})^{2}$ & $\mathrm{R}_{\mathrm{p}}=\mathrm{R}_{\mathrm{ct}}\left(\Omega \mathrm{cm}^{2}\right)$ & Chi-square & $\mathrm{IE}_{\%}$ \\
\hline Untre. & 31.255 & 283.6 & $3.5 \mathrm{E}+00$ & -- \\
\hline $2 \%$ & 40.14 & 768.2 & $6.7 \mathrm{E}+00$ & 63 \\
\hline $4 \%$ & 15.30 & 676.9 & $2.4 \mathrm{E}+00$ & 58 \\
\hline $6 \%$ & 29.73 & 973.6 & $7.4 \mathrm{E}+00$ & 70 \\
\hline
\end{tabular}

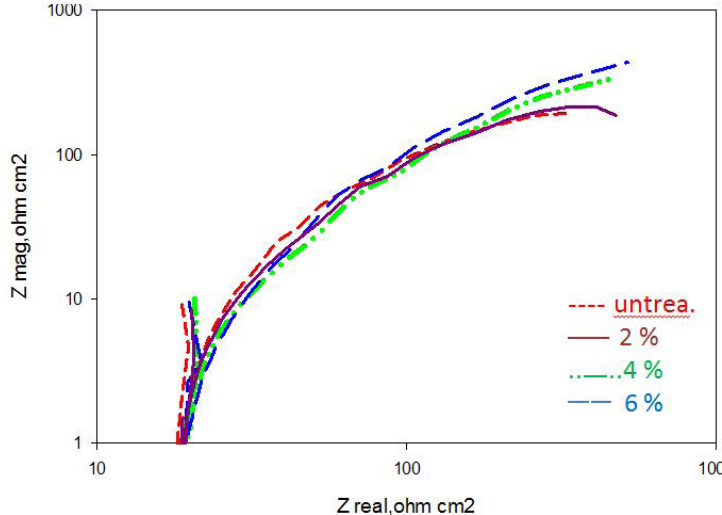

Figure 8. Nyquist plots for the coupons without and with various concentrations of OGE: Untreated, $2 \%, 4 \%$ and $6 \%$ concentration.

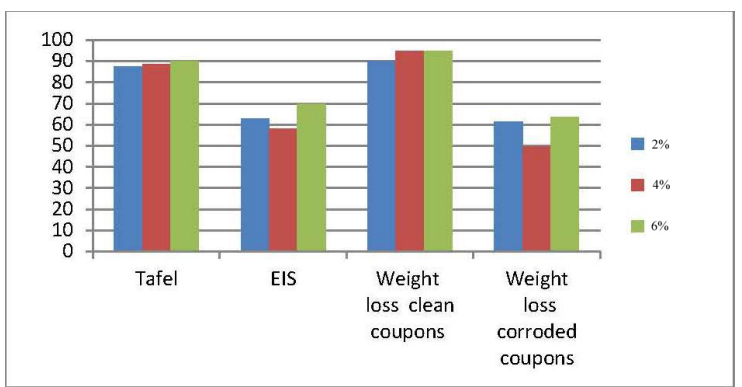

Figure 9. bar diagram shows inhibition efficiency comparison of OGE concentrations at the three tests.

when polarization is due to a combination of kinetic and diffusion processes. The diffusion process of inhibitor's ions take place on metallic coupons surface after the addition of the inhibitors especially green inhibitors. This Diffusion process can also create impedance called Warburg impedance. The impedance in this case depends on the frequency of the potential perturbation, when frequencies are high the Warburg impedance is low since diffusing reactants do not have to move very far. While at low frequencies, the Warburg-impedance is high due to the far diffusion of the reactants.

\subsection{Mechanism of corrosion inhibition and the nature of adsorption}

The protection mechanism of corrosion inhibitors differs from a compound to another. Some mechanisms depend on the specific ability to react with the surface (iron cations) of a metal and a protective film forms on the surface. This protective film is often an insoluble compound. This mechanism clearly appears in compounds containing $\mathrm{N}, \mathrm{S}$, and $\mathrm{O}$ atoms and these inhibitors often have high inhibition efficiency. These atoms are called heteroatoms and they represent the active center for the absorption process of inhibitors on a metal surface. The inhibition efficiency should follow the sequence $\mathrm{O}<\mathrm{N}<\mathrm{S}<\mathrm{P}^{40-42}$.

OGE contains many components and thus attributing the inhibition efficiency to a compound or two is not accurate, as the inhibition of most constituents of the extract occurs simultaneously. The previous analysis of the OGE powder reported that the extract mainly consists of hydroxyl aromatic compounds containing $\mathrm{OH}^{-}$group and oxygen heteroatoms such as tannic and gallic acid, flavonoids, and glycosides. Gallic, tannic, and ellagic acid are considered the main active components of OGE. The presence of a heterooxygen atom and $\mathrm{OH}^{-}$group, as an electronegative functional group, in the structure of those compounds make it possible for adsorption and bonding with the surface to be high. The adsorption is by coordinate type linkage through the transfer of lone pairs of electron of oxygen atoms and $\mathrm{OH}^{-}$group to the surface giving a stable chelate five-membered ring with ferrous ions (as shown in Figure 10) $)^{2,43-46}$. At the end, a blockage occurs of micro anodes. Therefore, the inhibitive effect of OGE is attributed to the formation of insoluble complex compounds between molecules of the extract compounds and and $\mathrm{Fe}^{2+}$ cations because these components are ligands ${ }^{2}$. Tannic acid is thought to form a passivating layer of tannates on the metallic surface especially at defective sites in surface or its corroded patina. The coherent inhibitor layer on the surface acts as a physical barrier to impede the attack of the surrounding medium ions by preventing the electrolyte reaction with the surface ${ }^{19}$, Also, the inhibitor layer prevents the adsorption of aggressive ions especially at defective sites already existing on the surface or corrosion patina film. 

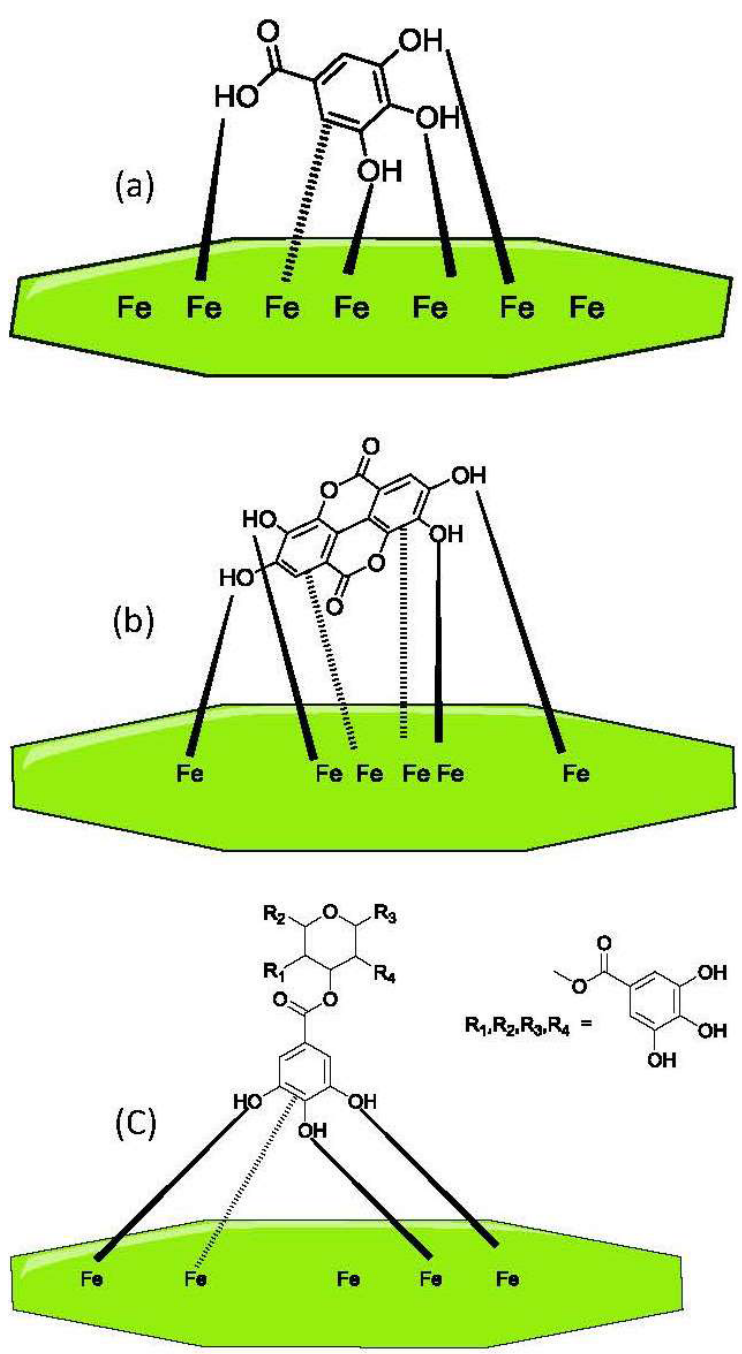

Figure 10. Skeletal representation of adsorption of the main active components of OGE on the HCS surface: (a) Gallic acid $\mathrm{C}_{7} \mathrm{H}_{6} \mathrm{O}_{5}$, (b) ellagic acid $\mathrm{C}_{14} \mathrm{H}_{6} \mathrm{O}_{8}$ and (c) tannic acid $\mathrm{C}_{76} \mathrm{H}_{52} \mathrm{O}_{46}$.

\subsection{Biocorrosion and prevention by green inhibitors}

Biocorrosion is related to the presence of microorganisms, especially bacteria that adhere to surfaces and enhance the occurrence of corrosion. Some authors have reported that phenolic acids of oak galls such as gallic, tannic, and ellagic acid have multiple biological effects and these compounds have the ability to become antioxidant, antimicrobial, antibacterial, and antifungal agent ${ }^{6,16,37}$. So, the use of OGE as green corrosion inhibitor will diminish the growth of microorganisms and prevents the occurrence of biocorrosion in addition to prevent the reaction with the surrounding corrosion media.

\section{Conclusion}

The results of different tests are various but the main conclusions are as follows:
- Results suggest that OGE has good inhibition properties as a green corrosion inhibitor against corrosion of archaeological carbon steel artifacts in an indoor museum environment.

- $\quad$ OGE is adsorbed on the metal surface and behaves as mixed-type inhibitors.

- The results obtained from the polarization curves demonstrated that OGE has high inhibition values.

- The humidity chamber test in $85 \% \mathrm{RH}$ has shown that the extract inhibits oxidation processes of high carbon steel coupons and the inhibition efficiency could be reached as high as up to $95 \%$.

- Tannic, gallic, and ellagic are the major components that are responsible for the inhibition action of OGE.

- The SEM analysis showed that the adsorption and coverage of the tested inhibitor on the coupons was very high.

- OGE doesn't cause a change in appearance or color of high carbon steel coupons whether corroded or un-corroded.

- Previous studies reported that OGE has an antimicrobial, antibacterial and antifungal agent.

\section{Acknowledgments}

I would like to thank Dr. Mai Rifai, Con. Dep., Arch. Fac., Cairo Uni., for all assistance and Mohammed shaepan, Agr. Fac., South valley uni., for preparation of OGE.

\section{References}

1. Eggert G, Scott DA. Iron and Steel in Art: corrosion, colorants, conservation. London: Archetype Publications; 2009.

2. Pelikán JB. Conservation of Iron with Tannin. Stu. in Con. 1966;11(3):109-15.

3. Farrer TW, Biek L, Wormwell F. The role of tannates and phosphates in the preservation of ancient buried iron objects. J Appli Chem. 1953;3:80-4. http://dx.doi.org/10.1002/ jetb.5010030206.

4. Wikipedia [homepage on the internet]. Tannin [cited 2020 Oct 11]. c2001-2020. Available from: https://en.wikipedia.org/wiki/ Tannin.

5. Puupponen-Pimiä R, Nohynek L, Meier C, Kähkönen M, Heinonen M, Hopia A, et al. Antimicrobial properties of phenolic compounds from berries. J Appl Microbiol. 2001;90(4):494507. http://dx.doi.org/10.1046/j.1365-2672.2001.01271.x.

6. Kaur G, Hamid H, Ali A, Alam MS, Athar M. Anti-inflammatory evaluation of alcoholic extract of Galls of Quercus Infectoria. J Ethnopharmacol. 2004;90(2-3):285-92. http://dx.doi.org/10.1016/j. jep.2003.10.009.

7. Hussein AO, Mohammed GJ, Hadi MY, Hameed IH. Phytochemical screening of methanolic dried galls extract of Quercus infectoria using gas chromatography-mass spectrometry (GC-MS) and Fourier transforminfrared (FT-IR). J. Pharm.and Phyto. 2016;8:49-59. http://dx.doi.org/10.5897/JPP2015.0368.

8. Samuelsson G, Bohlin L. Drug of natural origin: A Textbook of Pharmacognosy. 4th ed. Stockholm, Sweden: Swedish Pharmaceutical Press; 2004.

9. Nur Saeida B, Hasmah A, Wan Nor Amilah WAW. Potential use of Quercus infectoria gall extracts against urinary tract pathogenic bacteria. Int. J. of Res. in Pharmacology \& Pharmacotherapeutics. 2014;3(3):184-196. 
10. Zulkifli F, Nora'aini A, Sukeri M, Yusof M, Isa MIN, Nik WB. Henna leaves extract as a corrosion inhibitor in acrylic resin coating. Prog Org Coat. 2017;105:310-9. http://dx.doi. org/10.1016/j.porgcoat.2017.01.017.

11. Chellouli M, Chebabe D, Dermaj A, Erramli H, Srhiri A. Corrosion inhibition of iron in acidic solution by a green formulation derived from Nigella sativa L. Electrochim Acta. 2016;20420:50-9. http://dx.doi.org/10.1016/j.electacta.2016.04.015.

12. El-Etre AE, Abdallah M. Natural honey as corrosion inhibitor for metals and alloys. II. C-steel in high saline water. Corros Sci. 2000;42:731-8.

13. Ripper BDA, Perrone D, De Tecnologia C, De Janeiro R. Roasted coffee extracts as corrosion inhibitors for mild steel in HCL Solution. Mater Res. 2016;19:1276-85. http://dx.doi org/10.1590/1980-5373-mr-2015-0740.

14. Hamilton DL. Methods of conserving archaeological material from underwater sites. Texas: Texas A\&M University: 1999.

15. Mohammadim Z, Rahsepar M. Characterization of Mazuj galls of Quercus infectoria tree as green corrosion and scale inhibitor for effective treatment of cooling water systems. Res Chem Intermed. 2018;44:2139-55.

16. Saravanamoorthy $\mathrm{S}$, Velmathi S. Physiochemical interactions of chiral Schiff bases on high carbon steel surface: corrosion inhibition in acidic media. Prog Org Coat. 2013;76(11):152735. http://dx.doi.org/10.1016/j.porgcoat.2013.06.003

17. Walker R. The corrosion and preservation of iron antiques. $\mathrm{J}$ Chem Educ. 1982;59:943-7.

18. Rifai MM, Abdel Hamid Z, Saleh SM, Abdelbar MM. Evaluation of new coatings for the protection of ornamental cast ironwork exposed in uncontrolled environment. Int J Conserv Sci. 2015;6:611-24

19. Abu-Baker AN, MacLeod ID, Sloggett R, Taylor R. A comparative study of salicylaldoxime, cysteine and benzotriazole as inhibitors for the active chloride-based corrosion of copper and bronze artifact. Eur Sci J. 2013;9:1857-81.

20. Hollner S, Mirambet F, Texier A, Rocca E, Steinmetz J. Development of new non-toxic corrosion inhibitors for cultural property made of iron and copper alloys. In: Argyropoulos V, Hein A, Abdel Harith M, editors. Proceedings of the International Conference on Conservation Strategies for Saving Indoor Metallic Collections, Cairo. Proceedings. Athena: TEI of Athens; 2007. p. 156-61.

21. Fidrusli A, Suryanto S, Mahmood M. Ginger extract as green corrosion inhibitor of mild steel in hydrochloric acid Solution. IOP Conf Series Mater Sci Eng. 2017;290:214-22.

22. Hapidin H, Rozelan D, Abdullah H, Nurhidayah W, Hanaffi W, Soelaiman IN. Quercus infectoria Gall extract enhanced the proliferation and activity of human fetal Osteoblast Cell Line (hFOB 1.19). Malays J Med Sci. 2015;22:12-22.

23. Mohammed AAE, De Keersmaecker M, Adriaens A. Inhibition of the corrosion of iron heritage objects after treatmentwith long-chain monocarboxylic acids in ethanolic solutions. Prog Org Coat. 2016;101:225-32.

24. Ibrahim MM, Mohamed SO, Hefni YK, Ahmed AI. Nanomaterials for Consolidation and Protection of Egyptian Faience form Matteria, Egypt. Journal of Nano Research. 2019;56:39-48.

25. Askari HS, Abu-Hijleh B. Review of museums' indoor environment conditions studies and guidelines and their impact on the museums' artifacts and energy consumption. Buil. and Env. 2018;143:186-95.

26. Ingo GM, Angelini E, Riccucci C, de Caro T, Mezzi A, Faraldi F, et al. Indoor environmental corrosion of Ag-based alloys in the Egyptian Museum (Cairo, Egypt). Appl Surf Sci. 2015;326:222-35.

27. Salem Y. The influence of gaseous pollutants on silver artifacts tarnishing. Open J. of Air Poll. 2017;6:135-48. http://dx.doi. org/10.4236/ojap.2017.64011.

28. Chetouani A, Hammouti B, Aouniti A, Benchat N, Benhadda T. New synthesised pyridazine derivatives as effective inhibitors for the corrosion of pure iron in $\mathrm{HCl}$ medium. Prog Org Coat. 2002; $45: 373-8$.

29. Lgamri A, Abou El Makarim H, Guenbour A, Ben Bachir A, El Hajjaji S. Electrochemical study of the corrosion behaviour of iron in presence of new inhibitor in $1 \mathrm{M} \mathrm{HCl}$. Prog Org Coat. 2003;48:63-70.

30. Shimaa M, Khadijah A, Emran M, Messali M. Improved protection performance of modified sol-gel coatings with pyridinium-based ionic liquid for cast iron corrosion in $0.5 \mathrm{M}$ $\mathrm{HCl}$ solution. Prog Org Coat. 2019;130:226-34.

31. Hussin MH, Kassim MJ. The corrosion inhibition and adsorption behavior of Uncaria gambir extract on mild steel in $1 \mathrm{M} \mathrm{HCl}$. Mater Chem Phys. 2011;125(3):461-8. http://dx.doi.org/10.1016/j. matchemphys.2010.10.032

32. Chai C, Xu Y, Li D, Zhao X, Wu Y. Cysteamine modified polyaspartic acid as a new class of green corrosion inhibitor for mild steel in sulfuric acid medium: Synthesis, electrochemical, surface study and theoretical calculation. Prog Org Coat. 2019;129:159-70.

33. Khaled KF. Corrosion control of copper in nitric acid solutions using some amino acids - A combined experimental and theoretical study. Corros Sci. 2010;52:3225-34

34. Ostovari A, Hoseinieh SM, Peikari M, Shadizadeh SR, Hashemi SJ. Corrosion inhibition of mild steel in $1 \mathrm{M} \mathrm{HCl}$ solution by henna extract: A comparative study of the inhibition by henna and its constituents (Lawsone, Gallic acid, a-D-Glucose and Tannic acid). Corros Sci. 2009;51:1935-49.

35. Muresan L, Varvara S, Stupnisek-Lisac E, Otmacic H, Marusic K, Horvat-Kurbegovic S, Robbiola L, Rahmouni K, Takenouti H. Protection of bronze covered with patina by innoxious organic substances. Electrochem. Acta. 2007;52:2007-7770-9. https:// doi.org/10.1016/j.electacta.2007.02.024.

36. Khaled KF, Abdel-Shafi NS. Chemical and electrochemical investigations of L- Arginine as corrosion inhibitor for steel in hydrochloric acid solutions. Int J Electrochem Sci. 2013;8:1409-21.

37. Sukor N, Jusoh R, Rahim SA, Kamarudin N. Ultrasound assisted methods for enhanced extraction of phenolic acids from Quercus Infectoria galls. Mat. Tod. Pro. 2018;5:21990-9.

38. Rina R, Rafiquzzaman M, Hasmah A. Spectrophotometric determination of total Phenol and Flavanoid Content in Manjakani (Quercus Infectoria) Extracts. Heal. and Env. J. 2011;2:1-9.

39. Ashkenazi D, Nusbaum I, Shacham-Diamand Y, Cvikel D, Kahanov K, Inberg A. A method of conserving ancient iron artefacts retrieved from shipwrecks using a combination of silane self-assembled monolayers and wax coating. Corros Sci. 2017;123:88-102.

40. El-Etre AY, Abdallah M, El-Tantawy ZE. Corrosion inhibition of some metals using lawsonia extract. Corros Sci. 2005;47:38595.

41. Sawada S, Page CL, Page MM. Electrochemical injection of organic corrosion inhibitors into concrete. Corros Sci. 2005;47:2063-78.

42. Rani BEA, Basu BBJ. Green Inhibitors for corrosion protection of metals and alloys: an overview. Int J Corros. 2012;2012:1-15. http://dx.doi.org/10.1155/2012/380217.

43. Obot IB, Umoren S, Obi-Egbedi N. Corrosion inhibition and adsorption behaviour for aluminuim by extract of Aningeria robusta in $\mathrm{HCl}$ solution: synergistic effect of iodide ions. J. Mater. Environ. Sci. 2011;2:49-60.

44. Farooqi IH, Hussain A, Saini PA, Quraishi MA. Study of low cost eco-friendly compounds as corrosion inhibitors for cooling systems. Anti-Corros Methods Mater. 1999;46:328-35.

45. Fouda A, Shalabi K, Ezzat R. Evaluation of some thiadiazole derivatives as acid corrosion inhibitors for carbon steel in aqueous solutions. J. Mater. Environ. Sci. 2015;6:1022-39.

46. Ferraris S, Cazzola M, Ubertalli G, Prenesti E, Spriano S. Grafting of gallic acid to metallic surfaces. Appl Surf Sci. 2020;511:1-9. 